\title{
GESTÃO INTERNACIONAL DE RECURSOS HUMANOS E SEUS DESAFIOS: REVISÃO SISTEMÁTICA NO ENCONTRO DO SEMEAD DE 1998 A 2019
}

\author{
Vinicius Melchior dos Santos, Valdecir Cahoni Rodrigues \\ Universidade do Oeste Paulista - UNOESTE, Presidente Prudente, SP. E-mail: cahoni@unoeste.br
}

\begin{abstract}
RESUMO
Com o ápice da globalização na atualidade tem se tornado cada vez mais comum a inserção das organizações no mercado a nível global, o qual mostra-se mais competitivo e exigente com o passar do tempo. Tal mercado é atingido pelas organizações por meio da transferência de seus bens e serviços ao exterior, sendo considerado por boa parte das empresas como principal capital intangível, os recursos humanos, são peça fundamental da empreitada, transferidos de sua origem a locais estratégicos ao redor do mundo, com a função de cumprir missões pré determinadas, necessitando vivenciar novas esperiencias, em ambientes com diferentes culturas, valores e parametros de vida, tudo isto através do processo de expatriação. Do início ao fim do processo é de extrema importância que o indivíduo tenha o devido acompanhamento e amparo, que se faz por meio da gestão internacional de recursos humanos, setor essencial para o sucesso da inserção dos indivíduos e organizações no âmbito global. Justificando a existência do presente artigo, que trás uma contextualização a cerca dos seguintes tópicos, a) Mercado de trabalho; b) Gestão de pessoas; c) Expatriação; d) Motivos para expatriar; e) Dificuldades e obstáculos; f) Gestão internacional de recursos humanos. Tendo em vista seu objetivo geral de analisar como a gestão internacional de recursos humanos vem sendo abordada na literatura brasileira, questionamento o qual é respondido através da pesquisa qualitativa utilizando o método de revisão sistemática, nos eventos do SEMEAD (seminários em Administração) do ano de 1998 a 2019. Posteriormente a analise constatou-se que o tema ainda é pouco abordado na literatura brasileira, levando em consideração os resultados obtidos no evento analisado.
\end{abstract}

Palavras-chaves: Globalização. Expatriação. Gestão internacional de recursos humanos. Literatura brasileira.

\section{INTERNATIONAL MANAGEMENT OF HUMAN RESOURCES AND THEIR CHALLENGES: SYSTEMATIC REVIEW AT THE SEMEAD MEETING FROM 1998 TO 2019}

\begin{abstract}
With the apex of globalization nowadays, the insertion of organizations in the market at a global level has become increasingly common, which proves to be more competitive and demanding over time. Such a market is reached by organizations through the transfer of their goods and services abroad, being considered by most companies as the main intangible capital, human resources, are a fundamental part of the enterprise, transferred from their origin to strategic locations around the world. world, with the function of fulfilling predetermined missions, needing to experience new experiences, in environments with different cultures, values and parameters of life, all this through the expatriation process. From the beginning to the end of the process, it is extremely important that the individual has the proper monitoring and support, which is done through the international management of human resources, an essential sector for the successful insertion of individuals and organizations in the global scope. Justifying the existence of this article, which brings contextualization about the following topics, a) Labor market; b) People management; c) Expatriation; d) Reasons for expatriation; e) Difficulties and obstacles; f) International human resource management. In view of its general objective of analyzing how international human
\end{abstract}


resource management has been approached in Brazilian literature, the questionnaire or what is answered through qualitative research using the systematic review method, at SEMEAD events (seminars in administration) from 1998 to 2019. Subsequently, an analysis found that the topic is still little addressed in Brazilian literature, taking into account the results obtained in the analyzed event.

Keywords: Globalization. Expatriation. International human resource management. Brazilian literature.

\section{INTRODUÇÃO}

O capital intelectual assume de forma crescente a posição de principal ativo das organizações, pois permite que as informações se transformem em conhecimento, o que torna as empresas mais competitivas no mercado onde estamos inseridos, acompanhando o raciocínio dos autores Matos e Lopes (2008).

Atualmente a gestão de recursos humanos, segundo Oliveira (2017), tem como seu principal objetivo, promover e manter balanceado os interesses dos indivíduos e organizações. Tarefa essa que não se mostra nada fácil, e que necessita estar apoiada nos processos de promover, aplicar, manter, desenvolver e monitorar as pessoas dentro das organizações, sempre buscando maximizar a eficácia no relacionamento entre esses agentes do universo do trabalho.

Seguindo a ideia de Oliveira (2017), sendo assim, manter as pessoas nas organizações, tem se tornado um processo de grande importância entre todos os outros, já que o mesmo torna possível proporcionar harmonia no relacionamento tão complexo e importante, entre pessoas e organizações, direcionando-os para o sucesso mútuo.

A gestão de recursos humanos vem ocupando uma posição cada vez mais estratégica, buscando garantir vantagens competitivas no mercado, de acordo com Knapik (2012). Devido a isso, os gestores precisam gerar e difundir costumes de aprendizado contínuo, a fim de crescer economicamente e gerar novas competências nos indivíduos e organização, resultando assim nas vantagens competitivas e na sustentabilidade da organização.

Diz ainda knapik (2012) que os profissionais da área de recursos humanos têm como dever serem agentes de mudança, na preparação dos indivíduos para as exigências e ambições do mercado competitivo, e na busca de resultados, detectando e desenvolvendo principalmente atitudes capazes de suprir as exigências do mercado globalizado, sem deixar de lado os aspectos humanos das relações e a qualidade de vida.

Segundo os autores Kovacs, Moraes e Oliveira (2007), as mudanças na economia, tecnologias, e políticas com o passar dos anos, refletem no ambiente dos negócios, possibilitando e exigindo formas com que as empresas se tornem mais competitivas, com isso as organizações buscam otimizar seus processos internos e externos. Mudanças estas ocasionadas pela globalização, acarretando nas organizações a necessidade de alterações extremas para que essas possam se posicionar de forma eficiente frente aos desafios dos novos ambientes internacionais.

A movimentação de empresas para o mercado globalizado há muito tempo já faz parte do mundo dos negócios, principalmente para aquelas pertencentes a países com economias mais desenvolvidas, porém organizações estabelecidas em países de economias emergentes têm feito parte do processo de internacionalização, nestes últimos anos, conforme defendem os autores Silva, Orsi e Nakata (2013).

Uma das principais características da globalização nos últimos anos é a mobilização não só de capital e bens, mas a movimentação de colaboradores dos mais diferentes mercados, que se encontram abertos, extinguindo quaisquer tipos de fronteiras, tornando profissionais e organizações globais, afirmam ainda Silva, Orsi e Nakata (2013).

O crescimento acelerado da internacionalização nos últimos anos, conforme Lima e Braga (2010) ocasiona aumento da mobilidade internacional, tornando fundamental o conhecimento e entendimento dos problemas relacionados à gestão internacional de recursos humanos pelas organizações multinacionais, já que os desafios em meios internacionais são diferentes e mais complexos.

A gestão de recursos humanos é crítica para o sucesso operacional das organizações no meio de negócios internacional, conforme Silva, 
Orsi e Nakata (2013), faz-se de grande importância entender a maneira que a gestão de pessoas funciona nesse cenário multicultural, e como pode contribuir com o sucesso das organizações no mercado.

Devido à mobilidade entre países e a intensificação dos processos de internacionalização, dos patrimônios e das atividades empresárias, as práticas tradicionais de administrar os recursos humanos são desafiadas, possibilitando o desenvolvimento de carreiras internacionais, através do processo de expatriação, reconhece Borges (2011).

Expatriar traduz-se em uma experiência na qual se busca gerar benefícios mútuos, as organizações e também a carreira individual dos colaboradores expatriados, alega Freitas (2006). Para atingir tais benefícios, são necessários grandes investimentos de ambas às partes, da organização há todo o aparato financeiro, fornecido ao colaborador, que, mobiliza seus esforços para aprender e ser reconhecido por seu trabalho, conforme defendem os autores Bitencourt, Gallon e Scheffer (2014).

Frente às evidencias apresentadas o presente artigo, por meio de seu objetivo geral, busca responder ao questionamento de "como a Gestão Internacional de Recursos Humanos vem sendo abordada na literatura brasileira?" para obter tal resposta, realiza-se a revisão sistemática das edições de 1998 a 2019 do evento SEMEAD (Seminários em Administração). Para melhor fundamentação no assunto, os objetivos específicos são: a) Conceituar Gestão Internacional de Recursos Humanos; b) Demonstrar a importância da temática no cenário atual; c) Analisar publicações sobre Gestão Internacional de Recursos Humanos contidas nos eventos do SEMEAD (Seminários em Administração); d) Combinar os dados obtidos na analise e formular uma conclusão, buscando responder o questionamento realizado.

Devido ao mercado global ao qual fazemos parte e a quantidade ainda reduzida de estudos a respeito da Gestão Internacional de Recursos, torna-se importante a presente pesquisa de como a temática vem sendo abordada na literatura brasileira.

Atualmente grande parte das organizações almeja atuar no mercado internacional, meio onde a Gestão Internacional de Recursos humanos torna-se um fator importantíssimo, desta maneira, justificando a relevância do presente estudo.

\section{MERCADO DE TRABALHO}

Encontramo-nos atualmente em um mercado que vem sofrendo diversas adaptações devido à globalização e a internacionalização das organizações, resultando em um cenário onde a competição ocorre a nível global, tanto por espaço no mercado, quanto por recursos humanos qualificados, tendo este cenário em vista, os profissionais devem buscar desenvolver suas habilidades e competências com uma visão global, mantendo-se atualizados, conforme exige - mercado, cada vez mais competitivo e inconstante (CARDOSO, 2008).

Neste aspecto notam-se constantes mudanças em âmbito global e o avanço constante e veloz das tecnologias, portanto uma estrutura propicia para a adaptação do publico interno deve ser disponibilizada, buscando um aprendizado dinâmico e eficaz quanto ao que se é exigido, para que os mesmos estejam aptos a realizarem suas funções, não somente visando o cenário atual, mas estabelecer um padrão de constante evolução, consequentemente mantendo a organização juntamente aos indivíduos competitivo, em relação ao mercado futuro, e globalizado (VIEIRA, 2016).

Acompanhando o pensamento de Vieira (2016), deve-se sempre pensar que pessoas e as empresas se encontram inseridas em um mercado onde o atual já é passado, e o futuro é constituído no agora. Tendo isso, os indivíduos e organizações devem se posicionar com uma visão antecipada e planejamento, com intuito de criar estratégias e preparar-se, tendo em vista que ambos se encontram em um universo amplo (global), com diversos fatos acontecendo no agora.

\section{GESTÃO DE PESSOAS}

Segundo Chiavenato (2014), as organizações são como organismos vivos, em constante desenvolvimento, quando bem sucedidas tendem a crescer, ou no mínimo sobreviver. Consequentemente demandando de uma base mais aprimorada, com estruturas de operações mais complexas, novas tecnologias, e aumento do capital, o que gera crescimento no numero de pessoas envolvidas com a organização, juntamente com a necessidade de intensificar a aplicação de conhecimentos, habilidades e competências, de extrema importância para manutenção e competitividade da empresa. Com fim de garantir que todos os 
recursos disponíveis sejam utilizados com eficiência e eficácia.

Nota-se que independentemente da intensidade da globalização e dos avanços tecnológicos as organizações sempre precisam dos recursos humanos como principal diferencial e vantagem competitiva, pois são os reais responsáveis por manter, gerar e fortalecer inovações e o futuro das empresas, são os colaboradores que lideram, vendem, motivam, comunicam e fazem negócios (VIEIRA, 2016).

Os recursos são considerados como diferencial organizacional, responsáveis por sustentar e impulsionar o sucesso das empresas. Considerados como a principal competência e vantagem competitiva da organização, em um mundo globalizado, mutável, e altamente competitivo (CHIAVENATO, 2014).

Por consequência da concorrência incessável no mercado globalizado, faz-se importante que a gestão de recursos humanos, esteja hábil a aprimorar resultados, reduzir custos e simultaneamente a atrair e primordialmente reter profissionais capacitados e com potencial (VIEIRA, 2016).

Para utilizar e envolver as pessoas de forma plena nas funções a serem realizadas, os modelos organizacionais tem se alterado, no lugar de investir diretamente em produtos e serviços, as empresas vem direcionando seus investimentos em indivíduos que possuem habilidades e competências para criá-los, desenvolve-los e melhora-los, ao invés de investir em clientes, preferem investir em pessoas com capacidade atrai-los, que consigam identificar suas necessidades e sana-las. Gerando ganhos as organizações e tornando os recursos humanos o principal elemento para alcançar o sucesso (CHIAVENATO, 2014).

Chiavenato (2014) define gestão de recursos humanos como um relacionamento interdependente entre as pessoas e as organizações, sendo que, por um lado temos os indivíduos que necessitam das organizações para seu sustento, suprir alguns de seus desejos e como caminho para tornarem-se bem sucedidos. Do lado das organizações tem-se a necessidade das pessoas para alcançar objetivos, bater metas, satisfazer clientes e manterem-se competitivas no mercado. Tornando a relação entre ambas as partes em um ciclo de dependência e benefícios mútuos.

\section{EXPATRIAÇÃO}

A globalização e a internacionalização das empresas tem tornado constante a mobilidade de profissionais entre diversos países, mobilizados através da expatriação, são considerados expatriados os colaboradores de uma organização que são mandados para outro país por um determinado período de tempo, com fim de representar os interesses da empresa, no país destino, diz Figueiredo (2011).

Pode-se definir expatriação também como o ato de redefinir padrões, tanto para o profissional expatriado, quanto para seus acompanhantes, alterar rotinas, vivenciar novos costumes, modificar valores, integrar-se a diferentes redes de relacionamentos, criar uma infraestrutura nova, com o objetivo de atingir o bem-estar emocional dos indivíduos, os deixando preparados para enfrentar as dificuldades do processo (DAME; VERRUCK; LAZZARI; GONÇALVES, 2011).

Diferentemente da crença de muitos, a expatriação não é um processo recente, conforme defende a autora Cardoso (2008), desde o inicio da civilização indivíduos são enviados para o exterior, na época dos pioneiros do comercio internacional, nos séculos XVI e XVII, os expatriados tinham como objetivo a busca por novos mercados, produtos e terras, feito isto, passaram a serem enviados aos locais com o objetivo de representar a administração de subsidiarias, já após a Segunda Guerra Mundial, os expatriados serviam como apoio da matriz nas filiais espalhadas pelo mundo, considerados como representantes dos interesses da presidência da organização, tendo a responsabilidade por coordenar as operações, e a supervisão da disseminação do conhecimento e politicas corporativas. A seleção dos indivíduos a serem expatriados girava em torno do conhecimento e familiaridade para com os produtos, politicas e cultura da organização, a qual os incentivavam através da oferta de recursos financeiros (CARDOSO, 2008).

A expatriação esta voltada a um contexto mundial onde se busca compreender as consequências da globalização e da economia, relacionadas à movimentação social dos executivos, a administração intercultural e adequação às variadas culturas, sendo esta mobilidade a responsável pela formação de um novo perfil executivo, como o "executivo global" (DAME; VERRUCK; LAZZARI; GONÇALVES, 2011). 
Define-se o processo de expatriação como o envio de um indivíduo a fins de trabalho a um destino internacional, tendo elementos prédeterminados, como, função a ser realizado, período de permanência no exterior, podendo este período ser definido previamente ou não, condições financeiras e localização (NUNES et al, 2008 apud GALLON; ANTUNES 2016).

A gestão internacional de recursos humanos é utilizada pelas organizações por meio de três diferentes níveis de profissionais, segundo os autores Cavusgil, Knight e Riesenberger (2009), sendo eles: (1) Nativos do país anfitrião (NPAs), são os funcionários contratados diretamente do país onde se localiza a filial da empresa, os quais na maioria dos casos constituem a maior parte do quadro de funcionários nas organizações do exterior; (2) Nativos do país de origem da matriz (NPMs), conhecidos como cidadãos do país de origem, os NPM são originados do país onde se localiza a matriz da empresa multinacional; (3) Nativos de país estrangeiro (NPEs), estes são os colaboradores originados de outros países, que não o da matriz nem o da filial, grande parte dos NPE são contratados para cargos de gerencia, por apresentarem habilidades especiais. Diante disto, cabe à gestão da empresa decidir de acordo com suas necessidades qual será a categoria de expatriado a ser utilizada.

Podemos notar então que em organizações globais, é muito comum a presença de profissionais que atravessam fronteiras nacionais e assumem a responsabilidades e projetos específicos, que podem não ser cumpridos por qualquer um (CAVUSGIL; KNIGHT; RIESENBERGER, 2009).

\section{MOTIVOS PARA EXPATRIAR}

O processo de expatriação é tido para as organizações como uma medida estratégica, a qual as motiva por agregar no desenvolvimento profissional dos colaboradores e da liderança, expandirem seu mercado de atuação, solucionar problemas, exploração de novas tecnologias ou produtos e serviços (GALLON; SCHEFFER, 2015).

De acordo com o autor Tung (1981) apud Homem e Dellagnelo (2006), os expatriados são divididos em quatro tipos, enviados para suprir diferentes necessidades, sendo eles: (1) executivo oficial, principal colaborador responsável por gerenciar e dirigir as operações internas; (2) reprodutor de estrutura ou cabeça funcional, responsável por estabelecer departamentos funcionais, de forma a levar conhecimento gerencial e técnico da matriz para os membros das subsidiarias; (3) atacante de problemas, encarregado de analisar e resolver problemas operacionais específicos, aqueles que os colaboradores da filial não estão conseguindo solucionar; (4) enviado a uma filial com papel de ser um membro ou elemento comum na organização.

Posteriormente a analisarmos os tipos de expatriados apresentados pelos autores previamente citadas, podemos identificar que no passado as principais motivações das organizações a utilizar da expatriação tinham como fim solucionar problemas nas filiais estrangeiras, reproduzir conhecimento ou gerencia-las.

Diferentemente, as designações atreladas à expatriação em uma visão contemporânea, são ligadas à internacionalização da gestão organizacional, aumento de repertorio de conhecimentos, formação de novos lideres, desenvolver um projeto em uma unidade especifica, elevação do patamar de ordem e controle em todas as unidades, elevação da diversidade estratégica dos recursos humanos em face de mercados globais e ensinamentos a cerca da cultura da empresa mãe (FREITAS, 2006).

\section{DIFICULDADES E OBSTÁCULOS}

Alocar um indivíduo no exterior, principalmente em um meio cultural desconhecido, é uma experiência que sujeita a diferentes condições de vida e trabalho, impactando na reestruturação de sua rotina (PRESTES; ROSEMBROCK, 2015). De acordo com Machado e Hernandes (2004), as dificuldades relacionadas à cultura do país estrangeiro é a mais comum enfrentada por grande parte dos expatriados. A inserção na nova cultura torna-se mais simples quando o expatriado possui conhecimento do idioma local (MACHADO; HERNANDES, 2004).

Conforme ressaltam os autores Melo, Kovacs, Peixoto e Soares (2011), outra dificuldade a ser considerada no processo de expatriação, é má receptividade dos colaboradores do país de destino, tendo em vista a ideia de que os colaboradores estrangeiros tenham a preferencia para assumir cargos de gerencia, trazendo descontentamento e desmotivação aos trabalhadores locais, diante a esta situaçã̃o, as organizações tem buscado aperfeiçoar e valorizar 
os conhecimentos locais, optando por diminuir o uso contínuo de expatriados.

Além das influencias externas, há um fator interno com grande potencial a ser um obstáculo considerável no processo de expatriação, referente à posição profissional exercida pelo colaborador na empresa de origem, ou seja, caso o indivíduo esteja alocado em um cargo de muitas vantagens, será mais difícil criar estímulos à deslocação, neste caso, recomendase a escolha de um colaborador que anseia e necessita de um maior desenvolvimento em sua carreira profissional (MELO; KOVACS; PEIXOTO e SOARES, 2011).

Estudos realizados por Gallon, Scheffer, Bitencourt e Ives Gallon (2014), evidenciam a estimativa de que entre $20 \%$ a $40 \%$ dos colaboradores expatriados retornam prematuramente de sua missão.

Sendo assim, na visão de Prestes e Rosembrock (2015), transferir o cônjuge como acompanhante, se faz essencial, pois ao surgir insegurança a respeito da permanência no país de destino, é de grande importância que alguém próximo o lembre das vantagens disponibilizadas através desta experiência. Direcionados a família do profissional transferido como acompanhantes, pode-se identificar também algumas dificuldades a cerca da adaptação e no cotidiano da vida no exterior. O cônjuge e os filhos do profissional expatriado experimentam uma interrupção em seu modo de viver, relações, e vida diária, muitas vezes a resistência do cônjuge e de seus filhos, faz com que o profissional desista, com o objetivo de evitar maiores conflitos familiares (PRESTES; ROSEMBROCK, 2015).

Perante tudo isso, não é difícil compreender a extensão das dificuldades relacionadas ao processo de expatriação. Tendo em vista, da se a importância da escolha correta dos colaboradores, para serem enviados aos locais corretos, no momento correto de seu ciclo de vida, thes passando total ciência das adversidades e consequências, vantagens e desvantagens a qual estão sujeitos devido a tal processo (MELO; KOVACS; PEIXOTO e SOARES, 2011).

\section{GESTÃO INTERNACIONAL DE RECURSOS HUMANOS RECURSOS HUMANOS INTERNACIONAIS}

A ascensão dos negócios internacionais, gerada pela extinção das barreiras geográficas tem aumentado o fluxo de transações comerciais no mundo, neste contexto temos juntamente um notável crescimento no numero de profissionais que se dispõem a atuar no mercado estrangeiro (ROSAL, 2015).

Um dos desafios encontrados pelas organizações neste cenário globalizado é a adaptação de suas praticas de gestão de recursos humanos, de forma a tornar as operações confortáveis às organizações e colaboradores, tendo em vista as novas forças de trabalho resultantes de um ambiente multicultural (HOMEM; DELLAGNELO, 2006). Por tal razão, a gestão internacional de recursos humanos visa identificar aqueles indivíduos com características e habilidades específicas, exigidas para atuar no mercado internacional.

Desta maneira as organizações notam que para viabilizar conquistas de vantagens competitivas, o desempenho do setor de gestão internacional de recursos humanos é determinante, pois é através dela que se resulta no sucesso ou fracasso nos projetos internacionais (PRESTES; ROSEMBRCK, 2015).

O fenômeno da globalização ocasionado nos últimos anos, além de ser marcado pelo grande desenvolvimento tecnológico, e redução de barreiras, resultou também em uma maior interatividade entre pessoas de diferentes nações e culturas em todo o mundo, apontam as autoras Cardoso e Tanure (2008). Tais interações têm acarretado diversas influencias culturais nos profissionais e mercado internacionais.

Neste cenário as organizações têm de superar desafios, através de novas formas de gestão, para se desenvolver ou no mínimo sobreviver, dois grandes desafios trazidos a este contexto são: adequar-se ao meio externo e garantir sua coerência interna, adequar-se significa estar constantemente evoluindo, buscando maneiras de se manter competitivas. Garantir a coerência interna, necessita essencialmente ter pessoas executando de forma eficiente e eficaz suas funções, trabalhando com interdependência e harmonia, para tal, é necessário que os colaboradores interiorizem a essência da organização (HOMEM; DELLAGNELO, 2006). A gestão internacional de recursos humanos é responsável por capacitar os colaboradores a atingirem os objetivos previamente apresentados, ressaltando sua importância.

Tendo em vista que realizar o gerenciamento de pessoas em um contexto global se mostra exigir maior complexidade do 
que gerenciar pessoas em um ambiente nacional, surgiu à necessidade do desenvolvimento da Gestão Internacional de Recursos Humanos nas organizações (CAVUSGIL; KNIGHT; RIESENBERGER, 2009). Seguindo tal ideia dos autores, são os seguintes seis fatores que tornam a Gestão Internacional de Recursos Humanos mais complexos que a Gestão de Recursos Humanos nacional, sendo estes fatores:

Novas responsabilidades de Recursos Humanos, processos exigidos, não encontrados em âmbito nacional, como tributação internacional, serviços internacionais de mudanças e operações, administração de expatriados;

Necessidade de uma perspectiva internacional mais ampla na política de remuneração, reavaliação nas politicas de remuneração relacionas a profissionais de variadas nações, buscando a recompensação justa pelo trabalho realizado no país estrangeiro;

Maior envolvimento na vida dos trabalhadores, a Gestão de Recursos Humanos preocupa-se com o bem estar do expatriado e seus acompanhantes, com relação a condições, saúde, segurança, remuneração e educação;

Gerenciamento da combinação de expatriados e trabalhadores locais, as empresas devem em cada país ter pessoas do país de origem, do país acolhedor, e de países estrangeiros. Mesclando o pessoal de acordo com as habilidades e competências necessárias para a execução das atividades e a disponibilidade das mesmas;

Maior exposição aos riscos, em caso de queda na produtividade abaixo dos níveis aceitáveis, o expatriado volta ao país de origem, acarretando em grandes perdas de investimentos. Riscos políticos e terrorismo são também fatores levados em consideração.

Influências externas do governo e da cultura são fatores de fora do ambiente da organização que influenciam na vida do expatriado e acompanhantes, de maneira positiva ou negativa.

Por isso faz-se importante que o setor de gestão de recursos humanos acompanhe de perto o desenvolvimento e adaptação dos profissionais expatriados.

\section{RECRUTAMENTO E SELEÇÃO DO EXPATRIADO}

A gestão internacional de recursos humanos tem vital função no recrutamento e seleção de pessoas, tendo em vista que há necessidade de selecionar pessoas com habilidades e competências específicas, além de técnicas para gerenciar organizações em diferentes partes do mundo. Este processo é realizado atualmente no cenário de um mercado global, devido à extinção das barreiras geográficas (HOMEM; DELLAGNELO, 2006).

Um questionamento importante a ser levado em consideração ao dar inicio ao procedimento de recrutamento e seleção do profissional internacional, realizado por Sebben et al. (2009) apud Dame et al. (2011), "O executivo internacional nasce pronto ou é formado?". De maneira sucinta os autores respondem a tal questionamento, confirmando que determinadas características inatas contribuem para que o profissional se saia bem no cenário internacional, contudo outras competências tornam-se essencial seu processo de adaptação. Deste modo o recrutamento e seleção deve sim levar em consideração aspectos próprios da personalidade do individuo, juntamente com sua disponibilidade e flexibilidade de aprender diferentes formas de lidar com ambientes de negócios, tendo em vista que os expatriados não tem a capacidade de autodesenvolvimento (SEBBEN et al. 2009 apud DAME; VERRUCK; LAZZARI; GONÇALVES, 2011).

Os autores Cavusgil, Knight e Riesenberger (2009) enfatizam que as os indivíduos devem ser selecionados com cautela para atuarem internacionalmente, já que nem todos tem vocação para tal, aqueles que têm normalmente apresentam essas características:

Competência técnica: capacidade técnica de cumprir com as metas e objetivos da empresa;

Autoconfiança: visão empreendedora, proatividade, e forte sentido de inovação, já que na maior parte do tempo trabalhará de maneira independente;

Adaptabilidade: capacidade de se adaptar bem as culturas estrangeiras, empatia cultural, flexibilidade e diplomacia;

Habilidades interpessoais: construir e manter relacionamentos são de grande importância para gerentes, devido a grande interação social necessária;

Capacidade de liderança: bons gerentes encaram os desafios e ameaças, identifica oportunidades e trabalha de forma colaborativa com os outros funcionários para alcançar metas;

Saúde física e emocional: saber lidar com o estresse e com o choque cultural, para evitar ao máximo a necessidade de atendimento médico; 
O cônjuge e dependentes devem estar preparados: os acompanhantes do expatriado devem saber lidar com novos ambientes.

Apesar da existência de habilidades e competências atreladas ao perfil do executivo global, não se tem definido exatamente como deve ser o individuo que pretende alcançar este objetivo, segundo Cavusgil, Knight e Riesenberger (2009) o perfil do profissional internacional esta relacionado a pessoas independentes e aventureiras, sem medo de atravessar barreiras nacionais e culturais.

Prestes e Rosembrock (2015) os critérios utilizados para o recrutamento e treinamento de executivos expatriados são na maioria das vezes simplórios e rígidos, em determinadas empresas ainda se mantêm a lógica de que se o colaborado atinge ótimos resultados na organização do seu país, terá também este desempenho em qualquer outro lugar.

Os Recursos Humanos devem realizar a escolha correta do individuo a ser expatriado, baseando-se em suas habilidades, competências, motivações e projeções futuras, juntamente a fatores relacionados com a estabilidade e adaptabilidade familiar, pois estes são fatores de maior importância e decisivo para alcançar o sucesso da missão internacional (SOUZA, 2014).

Souza (2014) defende que a família tem um papel de extrema importância quanto a persistência do expatriado a continuar ou não no país de acolhimento, utiliza-se do seguinte argumento, no caso dos acompanhantes não receberem a estrutura apropriada para a permanência no exterior ou não conseguirem se adaptar, logo o expatriado terá a reação de abortar a missão, visando evitar conflitos familiares. Por outro lado, se a família estiver satisfeita e adaptada ao ambiente, e o expatriado sinta-se desestimulado e apresente sintomas de desistência, sua companhia pode influencia-lo a ficar relembrando as vantagens daquela experiência única.

Seguindo as ideias previamente apresentadas, pode-se afirmar então que, as organizações devem prestar apoio de maneira igualitária também a família do expatriado, introduzindo-os ao ambiente de maneira confortável, por meio de treinamentos, oferta de trabalho ao cônjuge e escola aos filhos (PRESTES; ROSEMBROCK, 2015).

\section{DESENVOLVIMENTO E TREINAMENTO DO EXPATRIADO}

Segundo os autores Cavusgil, Knight e Riesenberger (2009), o treinamento e a preparação são os meios de aumento da probabilidade de atingir os objetivos organizacionais, por meio da modificação das atitudes e aprimoramento dos conhecimentos dos colaboradores. Sendo de crucial importância para seu desempenho em ambientes estrangeiros.

Referente ao treinamento e desenvolvimento de profissionais que objetivam partir em missão no exterior concentra-se em preparo cultural, desenvolvimento de linguagem estrangeira, no gerenciamento da vida pessoal e familiar, e na realização de visitas preliminares, buscando gerar no indivíduo uma visão realista do que esperar do país de acolhimento (VIANNA; SOUZA, 2009).

$\mathrm{Na}$ visão de Cavusgil, Knight e Riesenberger (2009), o treinamento para colaboradores internacionais, conta com três componentes, sendo eles: (1) estudo da área conhecimento de assuntos históricos, políticos e econômicos do país destino; (2) informação prática - conhecimento e habilidade funcionais, incluindo moradia, saúde, educação e vida diária e (3) consciência intercultural - capacidade de interagir com pessoas de idiomas e culturas diferentes.

Os treinamentos podem ser aplicados de variadas formas, com diverso instrumento, afim de que o colaborador absorva o máximo de conhecimento possível, e consiga enfrentar os reais desafios, embasado no que the foi transmitido. Vídeos, palestras, leituras recomendadas, estudos de caso, livros, web treinamentos, análises, simulações, treinamento linguístico, experiência de campo e imersão, são alguns métodos utilizados nestes treinamentos, afirmam Cavusgil, Knight e Riesenberger (2009).

Para que o treinamento no país de origem seja mais efetivo, o setor ao qual o profissional será destinado deve realizar o acompanhamento do treinamento e desenvolvimento do individuo.

\section{REPATRIAÇÃO}

Após a conclusão da missão no estrangeiro a qual o expatriado foi mandado para cumprir, resulta-se no momento de regressar ao país de origem, esta etapa do processo é intitulada de repatriação. Da mesma forma que a 
expatriação, a repatriação necessita de planejamento prévio, caso não seja conduzida de forma correta o expatriado pode ter problemas ao retornar para casa (CAVUSGIL; KNIGHT; RIESENBERGER, 2009).

Nota-se a importância do planejamento da repatriação, e retenção dos indivíduos, devido ao alto investimento aplicado ao processo de expatriação, e mais que isso, em razão das competências adquiridas pelos executivos com a experiência internacional. Os mesmos passam a deter conhecimento de diversas culturas e contatos internacionais, além de compreender os negócios da organização com uma visão global, tornando tais profissionais um grande diferencial no mercado (LIMA; BRAGA, 2010).

Em média o expatriado custa internacionalmente de duas a três vezes mais para a organização, do que custaria se estivesse exercendo o cargo no país de origem, porém estes custos podem ser percebidos como investimentos retornáveis, e de valores expressivos, quando no processo de repatriação as competências e experiências obtidas pelo individuo no exterior são utilizadas pela empresa (LIMA; BRAGA, 2010).

Durante o período de expatriação pode haver alterações na organização de origem, como restruturações e atualizações na estratégia da organização, o individuo tende a mudar durante sua experiência internacional, sua identidade, visão de mundo e valores são redefinidos, da mesma forma acontece com sua família, por fim a cultura da organização pode não ser mais compatível com sua nova "versão" (LIMA; BRAGA, 2010). Este fenômeno é denominado como choque cultural reverso, onde o individuo sofre dificuldade para se adaptar ao seu antigo ambiente de trabalho e modo de vida, ao qual pertencia antes da expatriação (LIMA; BRAGA, 2010).

De acordo com Black et al. (1992) apud Tisott, Vieira, Lazzari e Camargo (2014), cerca de $20 \%$ a $25 \%$ dos indivíduos repatriados deixam suas empresas de origem no prazo de até um ano após sua volta, devido à insatisfação ou não readaptação com o ambiente e condições de vida, o que se mostra uma grande desvantagem, tanto para a empresa que perder o investimento efetuado no processo de expatriação, quanto para os repatriados que tinham como objetivo o desenvolvimento de uma carreira solida, através da internacionalização.
A readaptação do profissional no processo de repatriação está diretamente ligada ao reconhecimento profissional, oferta de cargo significativo pode minimizar as chances de problemas, contudo o processo tem relação também à manutenção de laços com os colegas do país de origem, manter contato frequente, fazer visitas à origem beneficia o colaborador juntamente à organização (VIANNA; SOUZA, 2009).

Levando em consideração o sucesso no processo de repatriação e que o colaborador tenha acumulado conhecimento e contatos consideráveis no exterior, a empresa tem o dever de presta-lo uma atenção especial, pois sua permanência na organização trará vantagens a ambas as partes (CAVUSGIL; KNIGHT; RIESENBERGER, 2009).

\section{MÉTODOS}

Objetivando analisar como a temática de Gestão Internacional de Recursos Humanos vem sendo abordada na literatura brasileira, a presente pesquisa se enquadra no método qualitativo, de acordo Cooper e Schindler (2016) este tipo de pesquisa auxilia o pesquisador a compreender como determinados fatos ocorrem (processos) e por que ocorrem (significado), segundo os autores a abordagem conta com técnicas que buscam descrever e entender o significado das coisas, visando uma compreensão profunda da situação, tal método foi escolhido pois permite uma melhor abordagem da temática.

Caracteriza-se também como uma pesquisa descritiva, conforme Barros e Lehfeld (2019) têm como objetivo estudar a relação entre variáveis de um fenômeno, mas sem os manipular. Visa o aprofundamento no estudo do objeto, descrevendo e registrando dados. Utiliza uma técnica padronizada de coleta de dados, objetivando responder o quem, como, quanto, onde e por que pesquisar, justifica-se sua escolha por se tratar de um método de estudo que não interfere nas variáveis abordadas.

Enquadra-se também como uma pesquisa bibliográfica, seguindo ainda os autores Barros e Lehfeld (2019), baseia-se na consulta de livros, artigos, periódicos, revistas, ou seja, qualquer espécie de documentação escrita, buscando a compreensão de um fenômeno. Sendo utilizada na obtenção de informações a respeito dos principais temas abordados no artigo, a) Mercado de trabalho, b) Gestão de 
pessoas, c) Expatriação, d) Motivos para expatriar, e) Objetivos e obstáculos, f) Gestão internacional de recursos humanos, e na obtenção dos dados coletados nos anais do SEMEAD (Seminários em Administração).

Quanto ao procedimento técnico, foi utilizada a revisão sistemática, que segundo os autores Cordeiro, Oliveira, Rentería e Guimarães (2007), consiste em uma investigação cientifica, tendo como objetivo reunir, avaliar de forma critica, e formular uma síntese dos resultados obtidos, buscando responder a um questionamento claramente realizado, através do uso de métodos sistemáticos e explícitos para identificar, selecionar e avaliar as pesquisas relevantes, coletar e analisar dados de estudos inclusos na revisão. A obtenção da resposta da problemática apresentada surge através da revisão sistemática das publicações do evento SEMEAD (Seminários em Administração) dos anos de 1998 a 2019, realizada da seguinte maneira:

Figura 1. Protocolo utilizado para a seleção dos artigos

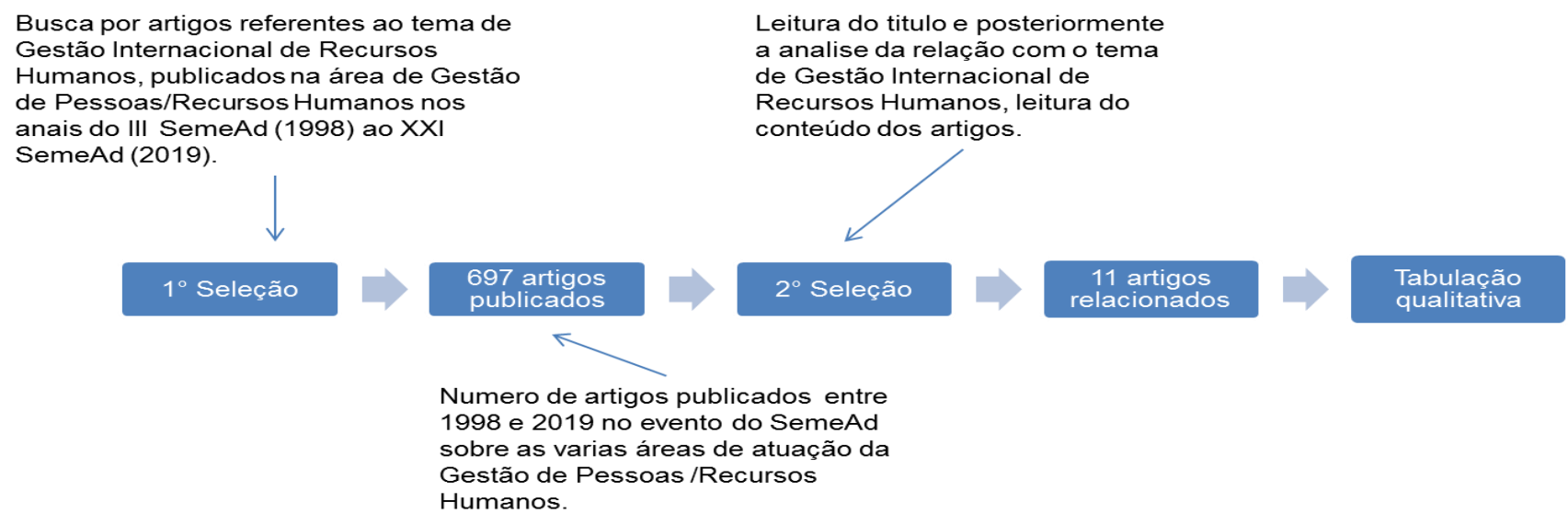

Fonte: $\mathrm{O}$ autor.

\section{RESULTADOS}

Esta sessão tem por objetivo expor os resultados obtidos através da analise sistemática aplicado, conforme os critérios previamente explicados na sessão anterior.

Foram pesquisados artigos do evento SemeAd (Seminários em Administração) dos anos de 1998 a 2019, ou seja, 21 edições, totalizando 697 artigos no tópico de gestão de pessoas, sendo que destes foram selecionados 11 periódicos de relevância, os quais se relacionam com a área de Gestão Internacional de Recursos
Humanos, e Expatriação, correspondentes a apenas $1,58 \%$ do total de artigos publicados ao decorrer dos anos.

No intuito de obter melhor compreensão a respeito do conteúdo de cada artigo selecionado, o quadro 1 expõe dados e informações em relação ao ano de publicação, autores, titulo, síntese dos objetivos, tema base, e métodos de abordagem de cada artigo. 
Tabela 1. Informações sobre os artigos selecionados

\begin{tabular}{|c|c|c|c|c|c|c|}
\hline $\begin{array}{l}\mathrm{N}^{\circ} \text { do } \\
\text { artigo }\end{array}$ & $\begin{array}{l}\text { Ano de } \\
\text { publicação }\end{array}$ & Autores & Titulo & Síntese do objetivo & Tema base & $\begin{array}{l}\text { Métodos de } \\
\text { abordagem }\end{array}$ \\
\hline 1 & 2005 & $\begin{array}{l}\text { Floriani e } \\
\text { Furlani }\end{array}$ & $\begin{array}{l}\text { Executivos } \\
\text { Expatriados em } \\
\text { Santa Catarina }\end{array}$ & $\begin{array}{l}\text { Identificar os } \\
\text { impactos causados } \\
\text { nas organizações } \\
\text { pelos } \\
\text { colaboradores } \\
\text { expatriados }\end{array}$ & Expatriação & $\begin{array}{l}\text { Pesquisa } \\
\text { qualitativa } \\
\text { através de } \\
\text { entrevista. }\end{array}$ \\
\hline 2 & 2008 & $\begin{array}{l}\text { Santos, } \\
\text { Gialain, } \\
\text { Silva e } \\
\text { Andrade. }\end{array}$ & $\begin{array}{l}\text { Desafios Culturais: } \\
\text { O Treinamento } \\
\text { Intercultural como } \\
\text { Diferencial na } \\
\text { Preparação n do } \\
\text { Expatriado. }\end{array}$ & $\begin{array}{lr}\text { Investigar } & \text { como } \\
\text { ocorre } & \text { o } \\
\text { treinamento } & \text { de } \\
\text { profissionais } & \text { para o } \\
\text { processo } & \text { de } \\
\text { expatriação. } & \end{array}$ & Expatriação & $\begin{array}{l}\text { Pesquisa } \\
\text { qualitativa, } \\
\text { através de } \\
\text { estudo de } \\
\text { caso } \\
\text { (observação } \\
\text { e entrevista). }\end{array}$ \\
\hline 3 & 2009 & $\begin{array}{l}\text { Nogueira, } \\
\text { Barreto e } \\
\text { Delgado. }\end{array}$ & $\begin{array}{l}\text { Gestão de } \\
\text { Recursos Humanos } \\
\text { no Processo de } \\
\text { Internacionalizaçã } \\
\text { o. }\end{array}$ & $\begin{array}{l}\text { Analisar o impacto } \\
\text { das estratégias de } \\
\text { internacionalização } \\
\text { no gerenciamento } \\
\text { de recursos } \\
\text { humanos }\end{array}$ & $\begin{array}{l}\text { Internacion } \\
\text { alização }\end{array}$ & $\begin{array}{l}\text { Pesquisa } \\
\text { qualitativa } \\
\text { exploratória, } \\
\text { através de } \\
\text { estudo de } \\
\text { caso } \\
\text { (observação } \\
\text { e entrevista). }\end{array}$ \\
\hline 4 & 2010 & $\begin{array}{l}\text { Barreto e } \\
\text { Nogueira }\end{array}$ & $\begin{array}{l}\text { Mentalidade } \\
\text { Global e Recursos } \\
\text { Humanos } \\
\text { Internacionais de } \\
\text { Empresas } \\
\text { Brasileiras. }\end{array}$ & $\begin{array}{ll}\text { Estudar } & \text { a } \\
\text { mentalidade global } \\
\text { de gestores de } \\
\text { empresas } \\
\text { brasileiras }\end{array}$ & $\begin{array}{l}\text { Mentalidad } \\
\text { e Global }\end{array}$ & $\begin{array}{l}\text { Pesquisa } \\
\text { qualitativa, } \\
\text { através de } \\
\text { estudo de } \\
\text { casos } \\
\text { múltiplos. } \\
\end{array}$ \\
\hline 5 & 2011 & $\begin{array}{l}\text { Carpes, } \\
\text { Scherer, } \\
\text { Beuron e } \\
\text { Lutz }\end{array}$ & 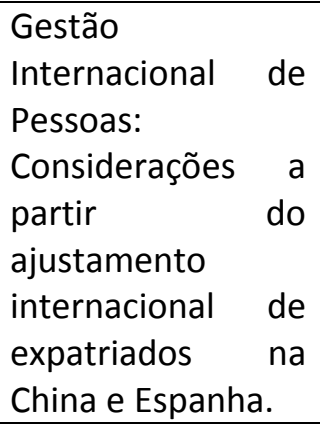 & $\begin{array}{l}\text { Estudar o processo } \\
\text { de ajustamento de } \\
\text { expatriados na } \\
\text { China e Espanha. }\end{array}$ & Expatriação & $\begin{array}{l}\text { Pesquisa } \\
\text { qualitativa, } \\
\text { através de } \\
\text { entrevistas. }\end{array}$ \\
\hline 6 & 2012 & $\begin{array}{l}\text { Carpes, } \\
\text { Beuron, } \\
\text { Madruga, } \\
\text { Schiavini e } \\
\text { Santos }\end{array}$ & $\begin{array}{l}\text { Estratégia de } \\
\text { Internacionalizaçã } \\
\text { o para a China e o } \\
\text { Reflexo no } \\
\text { Ajustamento } \\
\text { Internacional do } \\
\text { Executivo } \\
\text { Brasileiro } \\
\text { Expatriado. }\end{array}$ & $\begin{array}{lr}\text { Observar } & \text { como } \\
\text { ocorreu } & \text { o } \\
\text { ajustamento } & \\
\text { internacional } & \text { de } \\
\text { executivos } & \\
\text { brasileiros } & \text { na } \\
\text { China. } & \end{array}$ & Expatriação & $\begin{array}{l}\text { Pesquisa } \\
\text { qualitativa, } \\
\text { através de } \\
\text { entrevistas. }\end{array}$ \\
\hline 7 & 2012 & $\begin{array}{l}\text { Nakashima } \\
\text { ' Teixeira, } \\
\text { Mott e } \\
\text { Araújo. }\end{array}$ & $\begin{array}{l}\text { Expatriado: Um } \\
\text { Estudo } \\
\text { bibliométrico } \\
\text { Sobre Países Foco. }\end{array}$ & $\begin{array}{lr}\text { Conhecer } & \text { quais } \\
\text { países } & \text { tem } \\
\text { despertado } & \text { o } \\
\text { interesse } & \text { dos } \\
\text { autores nacionais e }\end{array}$ & Expatriação & $\begin{array}{l}\text { Pesquisa } \\
\text { quantitativa, } \\
\text { através de } \\
\text { dados da } \\
\text { Ebsco, }\end{array}$ \\
\hline
\end{tabular}




\begin{tabular}{|c|c|c|c|c|c|c|}
\hline & & & & $\begin{array}{l}\text { internacionais a } \\
\text { cerca do assunto. }\end{array}$ & & $\begin{array}{l}\text { Proquest e } \\
\text { Jstor. }\end{array}$ \\
\hline 8 & 2013 & $\begin{array}{l}\text { Scherer e } \\
\text { Minello }\end{array}$ & $\begin{array}{l}\text { Negócios na China: } \\
\text { Um Olhar da } \\
\text { Cultura Chinesa } \\
\text { por Brasileiros } \\
\text { Expatriados. }\end{array}$ & $\begin{array}{lr}\text { Analisar a } & \text { cultura } \\
\text { chinesa } & \text { com } \\
\text { relação } & \text { aos } \\
\text { negócios } & \text { na } \\
\text { percepção } & \text { de } \\
\text { expatriados } & \\
\text { brasileiros } & \end{array}$ & Expatriação & $\begin{array}{l}\text { Pesquisa } \\
\text { qualitativa, } \\
\text { através de } \\
\text { entrevistas }\end{array}$ \\
\hline 9 & 2013 & $\begin{array}{l}\text { Scherer, } \\
\text { Lisboa } \\
\text { Filho e } \\
\text { Fossá. }\end{array}$ & \begin{tabular}{lr}
\multicolumn{3}{l}{ Aspectos Culturais } \\
de vida & e \\
Trabalho: & Uma \\
Percepção & de \\
Chineses & que \\
Vivem no Brasil
\end{tabular} & $\begin{array}{l}\text { Analisar aspectos } \\
\text { culturais } \\
\text { relacionados à vida } \\
\text { e trabalho de } \\
\text { chineses que } \\
\text { moram no Brasil. }\end{array}$ & Expatriação & $\begin{array}{l}\text { Pesquisa } \\
\text { qualitativa, } \\
\text { através de } \\
\text { entrevistas. }\end{array}$ \\
\hline 10 & 2016 & $\begin{array}{l}\text { Luiz, } \\
\text { Ohrenstein } \\
\text { Oliveira, } \\
\text { Marinho e } \\
\text { Silva. }\end{array}$ & \begin{tabular}{ll} 
A & \multicolumn{2}{c|}{ Aprendizagem } \\
Organizacional & no \\
Processo & de \\
Expatriação. &
\end{tabular} & $\begin{array}{l}\text { Identificar fatores } \\
\text { que influenciam na } \\
\text { aprendizagem } \\
\text { através } \\
\text { expatriação. }\end{array}$ & Expatriação & $\begin{array}{l}\text { Pesquisa } \\
\text { exploratória } \\
\text { qualitativa, } \\
\text { através de } \\
\text { entrevista. }\end{array}$ \\
\hline 11 & 2017 & $\begin{array}{l}\text { Pinto, } \\
\text { Paula, } \\
\text { Moya, } \\
\text { Mendes e } \\
\text { Rodrigues. }\end{array}$ & $\begin{array}{lr}\text { Os } & \text { Desafios } \\
\text { Enfrentados } & \text { na } \\
\text { Construção } & \text { de } \\
\text { uma Carreira } & \\
\text { Internacional. }\end{array}$ & $\begin{array}{l}\text { ldentificar, } \\
\text { entender e analisar } \\
\text { os desafios } \\
\text { enfrentados por } \\
\text { profissionais na } \\
\text { construção de uma } \\
\text { carreira } \\
\text { internacional. }\end{array}$ & $\begin{array}{l}\text { Internacion } \\
\text { alização }\end{array}$ & $\begin{array}{l}\text { Pesquisa } \\
\text { qualitativa, } \\
\text { através de } \\
\text { entrevista. }\end{array}$ \\
\hline
\end{tabular}

Fonte: $\mathrm{O}$ autor,

Nota: Planilha realizada com base em dados do SemeAd (2020).

Referente aos objetivos dos artigos selecionados, o processo de expatriação e suas consequências é tido como foco em oito periódicos, sendo o primeiro publicado no ano de 2005, pelos autores Floriani e Furlani, tendo como foco identificar os impactos causados nas organizações por expatriados; o segundo, publicado em 2008, com autoria de Santos, Gialain, Silva e Andrade, uma analise investigativa de como são treinados os profissionais para a expatriação; consecutivamente 0 trabalho publicado no ano 2011, com autoria de Carpes, Scherer, Beuron e Lutz, buscando estudar o ajustamento de expatriados na China e Espanha; no ano seguinte, 2012, Carpes, Beuron, Madruga, Schiavini e santos, publicaram mais um trabalha com foco a observar como ocorreu o ajustamento de expatriados brasileiros na China; ainda no evento de 2012, Nakashima, Teixeira, Mott e Araújo, disponibilizaram uma pesquisa a cerca dos países foco de estudos sobre expatriação; no evento de 2013, Scherer e
Minello, publicaram um artigo com foco em analisar a visão da cultura chinesa através de expatriados brasileiros; permanecendo no evento de 2013, foi publicado um artigo buscando analisar aspectos culturais de profissionais chineses que residem no Brasil, com autoria de Scherer, Lisboa Filho e Fossá; o ultimo periódico do SemeAd com foco no processo de expatriação, foi publicado no ano de 2016, sendo os autores Luiz, Ohrenstein, Oliveira, Marinho e Silva, visando identificar fatores que influenciam na aprendizagem organizacional através da expatriação.

Além da expatriação outro tema base dos periódicos encontrados é a internacionalização, tendo dois artigos publicados no evento, o primeiro artigo publicado relacionado ao tema foi no evento de 2009, pelos autores Nogueira, Barreto e Delgado, uma analise sobre os impactos das estratégias de internacionalização no gerenciamento de recursos humanos; o segundo e ultimo artigo publicado focado no 
tema, em 2017, pelos autores Pinto, Paula, Moya, Mendes e Rodrigues, busca identificar, entender e analisar os desafios enfrentados pelos profissionais na busca por uma carreira internacional.

O ultimo tema relacionado à Gestão Internacional de Recursos Humanos, publicado no evento de 2010, teve como base a mentalidade global, com um único trabalho exposto, tem como autores Barreto e Nogueira, consiste em um estudo da mentalidade global de gestores brasileiros.

Cabe ressaltar que nas edições III (1998); IV (1999); V (2001); VI (2003); VII (2004); IX (2006); X (2007); XVII (2014); XVIII (2015); XXI (2018) e XXII (2019) do evento SemeAd não houveram publicações de artigos que se enquadrassem no tema pesquisado, Gestão Internacional de Recursos Humanos.

Nota-se que a metodologia mais utilizada nos artigos enquadrados é a pesquisa qualitativa, aplicada através de entrevistas, sendo utilizada em sete entre os onze periódicos, consecutivamente o método de pesquisa qualitativa, aplicada através de estudo de caso (observação e entrevista), é o segundo tipo mais aplicado, estando presente em três artigos, dentre todos os artigos, apenas um tem uma abordagem quantitativa a respeito do tema.

\section{DISCUSSÃO}

A presente pesquisa apresentou através da fundamentação teórica, o conceito de Gestão Internacional de Recursos Humanos, demonstrando sua importância no atual cenário, e analisou como a Gestão Internacional de Recursos Humanos vem sendo abordada pelos autores na literatura brasileira, considerando as publicações do III ao XXII SemeAd (Seminários em Administração), por meio da aplicação de revisão sistemática.

De acordo com os processos realizados constatou-se que a temática ainda vem sendo pouco investigada pelos autores integrantes do evento pesquisado, apresentando uma porcentagem baixa entre o numero total de artigos publicados na janela de tempo determinado. Contudo é evidente que dentre aqueles que se encaixam nos parâmetros da analise, tem o processo de expatriação como foco principal de sua abordagem, buscando compreender a adaptação, treinamento, aprendizagem, culturas estrangeiras as quais passam o profissional expatriado e as organizações.

Como limitações do presente artigo destaca-se a seleção de artigos unicamente nos eventos do SemeAd (Seminários em Administração) dos anos de 1998 a 2019, desconsiderando publicações de quaisquer outros eventos, anos anteriores, e idiomas estrangeiros. Deixando como sugestão para futuros trabalhos a pesquisa em diferentes eventos, e anos a respeito da área de Gestão Internacional de Recursos Humanos, a fim de atualizar a evolução do mesmo através do tempo.

\section{REFERÊNCIAS}

BARRETO, Maria Simone Prates; NOGUEIRA, Arnaldo Mazzei. Mentalidade global e Recursos Humanos Internacionais de Empresas Brasileiras. In: SEMINÁRIOS EM ADMINISTRAÇÃO, 13., 2010, São Paulo. Anais [...]. São Paulo: SemeAd, 2010.

BARROS, Aidil Jesus da Silveira; LEHFELD, Neide Aparecida de Souza. Fundamentos de metodologia cientifica. 3. ed. São Paulo: Pearson, 2019.

BITENCOURT, Betina Magalhães; GALLON, Shalimar; SCHEFFER, Angela Beatriz Busato. Programas trainee e expatriação como fatores propulsores de ascensão na carreira. ReCaPe Revista de Carreiras e Pessoas, São Paulo. v. IV, n. 03, set/out/nov/dez, 2014.

BORGES, Jacquelaine Florindo. Missão e carreira em terras estrangeiras: a expatriação verde e amarela de gestores corporativos. Revista Eletrônica de Ciência Administrativa (RECADM), Campo Largo, v. 10, n. 2, p. 31-47, jul-dez., 2011. Doi:

https://doi.org/10.5329/RECADM.20111002003

CARDOSO, Ana Paula Saldanha; TANURE, Betania. O processo de Ajustamento Intercultural de Expatriados Brasileiros, 2008. 105 f. Dissertação (Mestrado em Administração) - Pontifícia Universidade Católica de Minas Gerais, Belo Horizonte, 2008. Disponível em: http://www.biblioteca.pucminas.br/teses/Admini stracao CardosoAP 1.pdf. Acesso em: 27 nov. 2020.

CARPES, Aletéia de Moura; BEURON, Thiago Antonio; MADRUGA, Lúcia Rejane da Rosa Gama; SCHIAVINI, Janaina Mortari; SANTOS, Maríndia 
Brachak dos. Estratégia de Internacionalização para a China e o Reflexo no Ajustamento Internacional do Executivo Brasileiro Expatriado. In: SEMINÁRIOS EM ADMINISTRAÇÃO, XV., 2012, Santa Maria. Anais [...]. Santa Maria: UFSM, 2012.

CARPES, Aletéia de Moura; SCHERER, Flavia Luciane; BEURON, Thiago Antonio; LUTZ, Carolina. Gestão Internacional de Pessoas: considerações a partir do ajustamento internacional de expatriados na China e Espanha. In: SEMINÁRIOS EM ADMINISTRAÇÃO, XIV. 2011, Santa Maria. Anais [...]. Santa Maria: UFSM, 2011.

CAVUSGIL, $S$ Tamer; KNIGHT, Gary; RIESENBERGER, R. John. Negócios Internacionais: estratégia, gestão e novas realidades. São Paulo: Pearson, 2009.

CHIAVenato, Adalberto. Gestão de Pessoas: o novo papel dos recursos humanos nas organizações. 4. ed. Barueri: Manole, 2014.

COOPER, Donald R.; SCHINDLER, Pamela S. Métodos de pesquisa em administração. 12. ed. Porto Alegre: AMGH, 2016.

CORDEIRO, Alexander Magno; OLIVEIRA, Glória Maria de; RENTERÍA, Juan Miguel; GUIMARÃES, Carlos Alberto. Revisão sistemática: uma revisão narrativa, Comunicação Cientifica, Rio de Janeiro, v.34, n.6, nov./dez., $2007 . \quad$ Doi: https://doi.org/10.1590/S0100$\underline{69912007000600012}$

DAME, Maristela Sonda; VERRUCK, Fernando; LAZZARI, Fernanda; GONÇALVES, Roberto Birch. Processo de Expatriação e Repatriação de Funcionários em uma Multinacional do Setor Metalmecânico. In: ENCONTRO DO ANPAD ASSOCIAÇÃO NACIONAL DE PÓS-GRADUAÇÃO E PESQUISA EM ADMINISTRAÇÃO, XXXV., 2011, Rio de Janeiro. Anais [...]. Rio de Janeiro, 2011.

FIGUEIREDO, Mafalda. A Expatriação e o seu Impacto no Compromisso dos Colaboradores Expatriados. Lisboa: Instituto universitário de Lisboa, 2011.

FLORIANI, Dinorá; FURLANI, Kelly Ferreira, Executivos Expatriados em Santa Catarina. In:
SEMINÁRIOS EM ADMINISTRAÇÃO, VIII, 2005, Itajaí. Anais [...]. Itajaí, 2005.

FREITAS, Maria Ester de. Especial negócios internacionais: expatriação de executivos. GV : Executivo, v. 5, n. 48, set./out., 2006. Doi: https://doi.org/10.12660/gvexec.v5n4.2006.3422 $\underline{5}$

GALLON, Shalimar; ANTUNES, Elaine Di Diego. O Processo de Expatriação na Estratégia Organizacional, Revista Brasileira de Administração Científica, Rio Grande do Sul, v. 7, n. $1, \quad 2016.2$ Doi: https://doi.org/10.6008/SPC2179684X.2016.001.0004.

GALLON, Shalimar; SCHEFFER, Angela Beatriz Busato. Expatriação: uma Oportunidade de Repensar a Carreira. Revista Acance, Rio Grande do Sul, v. 22, n. 2, 2015. Doi: https://doi.org/10.14210/alcance.v22n2.p298$\underline{315 .}$

GALLON, Shalimar; SCHEFFER, Angela Beatriz Busato; BITENCOURT, Betina Magalhães; GALLON, Ives. Processo de Expatriação: além da experiência internacional. Gestão Contemporânea, Porto Alegre, n. 16, 2014.

HOMEM, Ivana Dolejal; DELLAGNELO, Eloise Helena Livramento. Novas Formas Organizacionais e os Desafios para os Expatriados. RAE eletrônica, São Paulo v.5, n.1 jan./jun. 2006. Doi: https://doi.org/10.1590/S1676$\underline{56482006000100009}$

KNAPIK, Janete. Gestão de pessoas e talentos. Intersaberes, Curitiba, 2012.

KOVACS, Erica Piros; MORAES, Walter Fernando Araújo; OLIVEIRA, Brigitte Renata Bezerra de. Redefinindo conceitos: um ensaio teórico sobre os conceitos-chave das teorias de internacionalização. Revista de Gestão USP, São Paulo, v. 14, n. esp., p. 17-29, 2007.

LIMA, Mariana Barbosa; BRAGA, Beatriz Maria. Práticas de recursos humanos do processo de repatriação de executivos brasileiros. Revista de Administração Contemporânea (RAC), Curitiba, v. 14, n. 6, dez., 2010. Doi: 
https://doi.org/10.1590/S1415-

\section{$\underline{65552010000700004}$}

LUIZ, Mayara de Aquino; OHRENSTEIN, Marina; OLIVEIRA, Maximiliano Souza de; MARINHO, Luciana Albino; SILVA, Natacha Bertoia da. A Aprendizagem Organizacional no Processo de Expatriação. In: SEMINÁRIOS EM ADMINISTRAÇÃO, XIX. 2016, São Paulo. Anais [...]. São Paulo, 2016.

MACHADO, Hilka Vier; HERNANDES, Cláudio Aurélio. Alteridade, Expatriação e Trabalho: Implicações para a Gestão Organizacional. RAC: Revista de Administração Contemporânea, Curitiba, v. 8, n. 3, jul./set. p. 53-73, 2004. Doi: https://doi.org/10.1590/S1415-

65552004000300004

MATOS, Florinda; LOPES, Albino. Gestão do capital intelectual: A nova vantagem competitiva das organizações. Lisboa: Scientific Electronic Library Online (SciELO), Lisboa, 2008.

MELO, António Filipe Peixoto Cordeiro Nunes; KOVACS, Ilona Zsuzsanna; PEIXOTO, João Alfredo dos Reis; SOARES, Maria Eduarda Mariano Agostinho. Objetivos e Dificuldades Inerentes ao Processo de Expatriação: o Caso das Empresas Portuguesas em Angola. 2011. Dissertação (Mestrado em Gestão de Recursos Humanos) Instituto Superior de Economia e Gestão, Universidade Técnica de Lisboa, Lisboa, 2011.

NAKASHIMA, Cleide; TEIXEIRA, Maria Luisa Mendes; MOTT, Michel; ARAÚJO, Gledston. Expatriação: um estudo bibliométrico sobre países foco. In: SEMINÁRIOS EM ADMINISTRAÇÃO, XV., 2012. São Paulo. Anais [...]. São Paulo, 2012.

NOGUEIRA, Arnaldo Mazzei; BARRETO, Maria Simone Prates; DELGADO, Monica Pereira. Gestão de Recursos Humanos no Processo de Internacionalização. In: SEMINÁRIOS EM ADMINISTRAÇÃO, XII., 2009. São Paulo. Anais [...]. São Paulo, 2009.

OLIVEIRA, Luciano Oliveira de. Gestão estratégica de recursos humanos, 2. ed. Porto Alegre: SAGAH, 2017.

PRESTES, Vanessa Amaral, ROSEMBROCK, Marcos Aurélio. O Processo de Expatriação: As Pessoas no Contexto Internacional. Caderno Cientifico Ceciesa: Gestão, v. 1, n. 1, 2015.

PINTO, Isabel Amorim Lacerda; PAULA, Letícia Rodrigues de; MOYA, Tatyana Grammenopoulos; MENDES, Ana Caroline; RODRIGUES, Miriam. Os Desafios Enfrentados na Construção de uma Carreira Internacional. In: SEMINÁRIOS EM ADMINISTRAÇÃO, XX., 2017, São Paulo. Anais [...]. São Paulo, 2017.

ROSAL, Anna Silva Rosal de. Gestão de Recursos Humanos Internacional e o Ajustamento Intercultural do Executivo Expatriado. Psicologia em Revista, São Paulo, v. 24, n. 1, 2015.

SANTOS, Heliani Berlato dos; GIALAIN, Eliana; SILVA, Natacha Bertoia da; ANDRADE, Sandra Mara de. Desafios Culturais: O Treinamento intercultural como Diferencial na Preparação do Expatriado. In: SEMINÁRIOS EM ADMINISTRAÇÃO, XI., 2008. São Paulo. Anais [...]. São Paulo, 2008.

SCHERER, Laura Alves; FILHO, Flavi Ferreira Lisboa; FOSSÁ, Maria Ivete Trevisán. Aspectos culturais de Vida e Trabalho: uma percepção de chineses que vivem no Brasil. In: SEMINÁRIOS EM ADMINISTRAÇÃO, XVI., 2013. Santa Maria . Anais [...]. Santa Maria: UFSM, 2013.

SCHERER, Laura Alves; MINELLO, Italo Fernando. Negócios na China: um olhar da cultura chinesa por brasileiros expatriados. In: SEMINÁRIOS EM ADMINISTRAÇÃO, XVI., 2013. Santa Maria . Anais [...]. Santa Maria: UFSM, 2013.

SILVA, Natasha Bertoia da; ORSI, Ademar; NAKATA, Lina Eiko. Analise da produção acadêmica sobre gestão internacional de recursos humanos entre 2001 e 2011, Revista de Carreiras e Pessoas (ReCaPe), São Paulo, v. 3, n. 3, set/out/nov/dez, 2013.

SOUZA, André Francisco Bastos. A Adaptação Intercultural da Família: Um Estudo Exploratório com Expatriados Portugueses, 2014, 119 f. Dissertação (Mestrado em Gestão e Desenvolvimento de Recursos Humanos) - Escola Superior de Estudos Industriais e de Gestão, Vila do Conde, 2014. Disponível em: https://recipp.ipp.pt/bitstream/10400.22/5502/1 /DM AndreSousa 2014.pdf. Acesso em: 24 nov. 2020. 
TISOTT, Priscila Bresolin; VIEIRA, Guilherme Bergmann Borges; LAZZARI, Fernanda; CAMARGO, Maria Emilia. Motivadores e Dificuldades do Processo de Expatriação de Executivos Brasileiros para a Índia, Espacios, v. 35, n. 6, 2014.

VIANNA, Nereida Prudêncio; SOUZA, Yeda Swirski de. Uma Análise Sobre os Processos de Expatriação e Repatriação em Organizações Brasileiras, BASE - Revista de Administração e Contabilidade da Unisinos, São Leopoldo, v. 6, n. 4, nov./dez., $2009 . \quad$ Doi: https://doi.org/10.4013/base.2009.64.05

VIEIRA, Vanessa Gomez. Fator Humano e a Busca da Qualificação Profissional como Diferencial Competitivo no Mercado Globalizado, Revista Inter Atividade, Andradina, v. 4, 2016. 